\title{
Challenges of Distance Learning in Language Classes: Based on the Experience of Distance Teaching of Arabic to Non-native Speakers in Light of the Coronavirus Pandemic
}

\author{
Dalal Moh'd Al-Assaf \\ Arabic Language to Non-native Speakers Department, Languages Center, The University of Jordan, Amman, Jordan
}

\begin{abstract}
This study aims to investigate the challenges that learners and teachers of a language face during distance learning classes, especially learners and teachers of the Arabic language as a second language, based on the results of a distance learning experiment on non-native speakers of the Arabic language at the University of Jordan during the second term of 2019-2020. The study seeks to introduce the proper solutions that may mitigate these challenges to achieve the educational goals through distance learning while teaching the Arabic language as a second language. This study used the applied descriptive approach in identifying these challenges. It concluded that these challenges significantly impact the language learning process, including mastering it, the extent of benefit, and the influence on students' linguistic progress. This study recommends that these challenges are considered when adopting distance learning as a language education method at teaching language classes as a second one. These challenges need to be considered when planning for direct and indirect lessons in Arabic language educational classes, primarily via the Internet.
\end{abstract}

Index Terms - distance learning, challenges, Arabic language education to non-Arabic speakers

\section{INTRODUCTION}

The continuous interest in teaching and learning languages, especially the Arabic language as a second language, resulted in establishing many schools, institutes, and centers interested in teaching languages to non-native speakers. Furthermore, there is more interest in the ways and methods of language education to keep up with the developments over time in different fields of education. The educational sector has utilized technology in language education. Teachers adopted technology to provide a suitable interactive environment to learn a language in a functional way, helping the student learn the language and acquire its various vocabularies, structures, and skills at all different levels. Wherein this environment motivates and attracts the students in the learning process and goal achievement, as well. Also, the technology proved its effectiveness in many educational programs and classes.

Moreover, many websites and online platforms took the lead in distance learning of languages, including teaching the Arabic language to non-native speakers. Teachers considered the virtual classes instead of the real classes at schools. This modern educational phenomenon came up with new technological development in the world. The goal was to provide an educational opportunity for students who cannot obtain it in the traditional circumstances due to the remoteness, the lack of enough money for studying abroad, or the inability to enroll in the regular class because it doesn't match the student's time or due to the inconvenient financial and health conditions of the student.

The interest in distance learning has increased in light of the world's current situation with the emergence of the coronavirus pandemic. Despite this, educational institutions attempt to maintain the education's progress in different ways by adopting distance learning to ensure the educational process's pertinacity due to the issue of attendance at the educational sites because of the preventive actions which the governments imposed. Distance learning has become a suitable way for various educational institutions to continue their academic goals. Despite the benefits that distance learning or E-Learning can bring, many challenges emerged in the distance learning field, particularly language teaching.

Accordingly, this study attempts to answer the following questions:

1 - What are the challenges that face the language learner through distance learning?

2- What are the challenges that face the language teacher through distance learning?

3- What are the challenges related to language teaching?

4- What are the challenges related to distance learning?

\section{THE IMPORTANCE OF THE STUDY}

This study investigates the challenges of distance learning in language classes, essentially teaching Arabic to nonArabic speakers. Moreover, it suggests some solutions that can mitigate the challenges and alleviate the negative impact 
on language distance learning and goal achievement.

The virtual learning and teaching environment may pose a great challenge to both students and teachers alike, specifically in the language classes, whether in terms of the availability of technological capabilities required for distance learning or psychological conditions for this type of education. Many students prefer to learn the language in an in-person environment and its cultural and linguistic community. It has a positive impact on gaining the language and practicing its skills or conformity of the school's curriculum and its linguistic and cultural content with distance learning nature, in addition to the teaching methods and their suitability to the students' different learning strategies in light of peculiarity of teaching methodological and stylistic languages, especially teaching the Arabic language in terms of its composition, structure, semantic and cultural dictionary, and a phonemic, morphological and grammatical system, in addition to other challenges.

\section{PREvious STUdies}

Many studies have dealt with E-Learning and educational technology in the context of discussing the development of education trends and methodologies, its benefits and its positive impacts on teaching and learning inside the classroom, its strategies, and the computerization of education as an indicator of the development of education strategies in this century, particularly at universities and other learning places. Some of these studies addressed obstacles to distance learning, whereas most of these studies focused on the economic factor and the extent of the necessary tools' availability. Besides, the technical support in schools and universities for this type of education, the teacher's unfamiliarity with distance learning techniques, and the need for suitable training to be utilized at their classes are obstacles to making distance learning successful.

I did not find - within the limits of my research - a study that focused on distance learning challenges for language classes, especially those related to teaching Arabic to non-Arabic speakers. Still, I found two studies that discussed the positive results of E-Learning and using technology in the classes of teaching Arabic to non-Arabic speakers.

1- Al Qudum, Mashael, "The Impact of Technology, and Modern Means of Communication on the Non-Arabic Speaking Learners" (2016). It is a doctoral thesis that consisted of three chapters to identify the impact of technology and the modern communication of non-Arabic speaking learners by identifying the level of technology use by learners. The thesis also seeks to determine whether there are statistically significant differences in the study sample when using technology in learning the Arabic language. This study used the descriptive analysis approach by distributing a questionnaire to a sample of 100 students from the languages center at the University of Jordan and 100 female students from the institute of teaching Arabic to non-Arabic speakers at the Princess Nourah Bint Abdul Rahman University in Saudi Arabia. This study concluded that the use of technology and the modern means of communication by non-Arabic speaking learners were moderate. Moreover, the study recommended that it is necessary to teach the Arabic language to non-native speakers from the traditional level to the online level. In addition to teaching Arabic teachers to use websites specializing in teaching Arabic to non-Arabic speakers, it leads to positive results in improving teaching Arabic to nonArabic speakers.

2- Al Haisa, Sharif. "The Impact of Using Interaction Patterns in the E-Learning Environment on Developing the Reading Skills of the Non-Native Speakers - Beginner Level" (2019). This Master's thesis consisted of five chapters to identify the learning styles in the E-Learning environment and the impact on teaching reading skills in Arabic to nonnative speakers at the beginner level. The sample consisted of 32 male and female students from the Languages Center at the University of Jordan and the University of Islamic Sciences. The study adopted the experimental method. The sample was divided into two experimental groups; the first group was taught through asynchronous interaction via email, while the second group was taught through the synchronous interaction method (chat rooms). The study concluded that the members of the synchronous learning group via chat rooms were learned more than the members of the asynchronous learning group via e-mail. This was concluded by the students' ability to read letters, shapes, and locations, learn the skill of synthesizing words from scattered letters, and compose sentences from scattered words.

This study investigates the challenges of distance learning in language classes, especially Arabic education classes, as it is not limited to the challenges of using technology and E-Learning within the classroom only. Still, instead, it tries to identify the challenges of teaching the language in virtual classes through the researcher's experience in teaching the Arabic language online in light of coronavirus pandemic; this is followed by proposed solutions to try to overcome these challenges and reduce their negative impact on the success of the distance learning process and the achievement of its objectives.

\section{Distance LeARning AND E-LEARNing}

Many people compare distance learning with E-Learning, and some believe that distance learning is the equivalent of E-Learning. E-Learning is much broader than distance learning. E-Learning is used inside and outside the classroom, and it invests technology in direct and indirect classroom lessons. This type of education came as a step in developing teaching methods, which used to rely on memorization as a basis for transferring knowledge to the student. In this way, students became an effective part of the educational process. They acquired knowledge through interactive activities and technology - the computer and its various programs and the use of the Internet, including educational websites and 
various programs, made the students rely on themselves in the learning process. New learning patterns and teaching appeared, and the teacher became the supervisor and the guide for the student and this educational process. (For more, see: (Salem, 2004, Al-Khan, 2005, Al-Omari, 2014)

Today, many universities are turning to the blended education that combines E-Learning and the traditional methods of teaching in regular classes (for more, see: Abu Musa, 2012, Al-Kilany, 2011)

Distance Learning is limited to virtual classes in which the teacher meets their students over the Internet, synchronously or asynchronously. The geographical distance is a fundamental reason for the emergence of this type of education, i.e., the presence of the learner in a place or country that differs from the location of the source of learning, whether it is a teacher, an educational institution, or a group of students in training courses (For more, see: Farkouh, Souad; 1989, Amer, Tariq Abdel-Raouf; 2007). Perhaps the recent global health crisis has contributed to the increased use of this type of education. Instead, distance learning has become an essential method to continue the educational process in schools and universities, especially since this health crisis began in the middle of the semester.

This sudden and rapid transition from the traditional classes that gather the teacher and the student in one place to the virtual classes in which they meet via the Internet posed a challenge to them at the same time, especially for those who are not accustomed to using this method.

Perhaps this matter is less difficult for students and teachers in the same country as students attending local schools and universities. We find a bigger challenge for the institutions whose programs teach languages, especially teaching Arabic - in the context of our Arab society - to students who came to study the language in its environment and society, but the circumstances forced them to return to their countries in light of coronavirus pandemic. The challenges related to the geographical distance, which necessitated distance learning - have become more prominent and their association with the time difference between the students themselves and the teacher.

Teaching a language to non-native speakers has a specificity and depends on many foundations (see: Brawn, 1994, Nageh, 2018). It has special considerations that ensure its success and achievement of goals. The most important of them are students' interaction and in the societal, educational environment and the interactive functional activities and exercises that help them acquire language skills in listening, reading, writing, and speaking, in addition to practicing these skills in an appropriate environment and performing their functions across the different linguistic levels. Besides, it seems more difficult in light of teaching the Arabic language: linguistically, synthetically, culturally, and socially.

\section{Challenges of Distance Learning in Language Classes}

Language learners and teachers face many challenges when using distance learning, especially language learning for non-native speakers. These challenges can be divided into the following categories:

\section{A. Challenges Related to Students}

\section{Psychological challenges:}

There is no doubt that the psychological factor plays an important role in the success or lack of success in this learning method. The psychological readiness of students to use distance learning after they were in a real class meeting with the teacher, and their acceptance of the surrounding circumstances regardless of the differences that occur, and the subsequent change like the educational class in light of this global health crisis is reflected in the success of distance learning process. Students may be less motivated to learn under these circumstances, and students may feel frustrated or anxious about not being able to benefit from the language class and achieve their educational goals. The surrounding conditions of the family and health may affect the psychological readiness to learn the language and practice its skills and carry out the teacher's duties; this is especially true if the students started their studies in the language and its society, then circumstances forced them to return to their countries. Therefore, the psychological readiness to learn a language online is necessary for everyone who wants to learn in this way, regardless of the surrounding circumstances. The student must be aware of the consequences of this type of learning in terms of spending time in front of a computer screen without interaction with the learning environment, and his inability to attract the teacher's attention and receive direct and continuous follow-up on his performance as if he were in a normal classroom which is different from the virtual class's environment.

\section{Technological challenges:}

The technological and technical readiness of students is also very important. This type of education is mainly based on the use of technology and modern means of communication. We cannot be certain that all students have this readiness, possess the same capabilities, technological means, and technical skills. Therefore, language teachers may use several programs, platforms, or websites to create a successful interactive classroom; this may not be easy if the student cannot use these programs and sites. It may require additional time and effort from the teacher to help the student familiarize himself with these technical matters and how to use them to integrate the student into the educational classroom and benefit from its processes and activities and achieve the goal of joining it. It is learning the language and its skills, and the ability to communicate with it, and the progress in language performance that define language learning success.

Geographical Distance:

The geographical distance and the difference in time are challenges for the student and the teacher alike. The 
language class usually includes students from different nationalities and countries united by the physical class within a study program with a fixed time suitable for all. Whereas shifting to distance learning in light of this global health crisis and students returning to their countries cost the students and the teacher the trouble of searching for a time that suits everyone, and if the classes went in their normal time, some students were deprived of the opportunity to continue joining the classes because the time was not suitable for them. Besides, the Internet connection problems due to the geographical distance and the time difference between different parts of the world are difficult to manage.

\section{Learning method and strategies:}

Learners face some challenges that are related to the learning strategies. Students generally differ in how they receive and acquire information, whether visual, auditory, kinesthetic, etc. Perhaps, the traditional classroom provides greater diversity in the way students are presented with information and educational content. It may accommodate these different strategies and better meet students 'needs that distance learning or E-Learning.

\section{B. Challenges Related to the Teacher}

Language teachers face several challenges in the distance learning process, and most of them are related to the challenges that students face. These challenges are:

\section{Psychological conditions:}

The psychological conditions that the student is going through will face the teacher in his country as well, as this health crisis is global. Many teachers may be concerned about the possibility of achieving the planned educational goals under these circumstances, in light of the rapid transition to distance learning, and, in light of the psychological and technological conditions that students experience, in addition to the change in location for many students and the changes in the classroom time. Moreover, tension and psychological pressure about the students' benefit from the language class and their ability to meet their language needs consider their differences and the appropriate learning method.

The teacher should not be tense when meeting his students via the Internet. Still, he must be their role model in facing these psychological conditions, encouraging them to continue the learning process, and motivating them through his cheerful, optimistic facial expressions, his words of encouragement, and launching the virtual classroom with energy and enthusiasm. This is in addition to creating an interactive class that includes language activities that make the student feel the value and the importance of the language class, even if it is online.

\section{Technological Readiness:}

Students' technological and technical readiness to complete the distance learning process will be reflected in their communication with the teacher and their ability to follow the lessons. Any technical or technological problem will affect communication with the teacher and the continuation of the classes. Perhaps technological readiness and having technical skills are not limited to students alone, as many teachers do not have sufficient knowledge of using technological means and modern means of communication and how to employ them in their classrooms (see: Al-Otaibi, 2006; Al-Hawamdeh, 2011). In particular, distance learning is not limited to direct contact between the teacher and his students to provide lessons in an instructional manner, as this will not help achieve educational goals, and there is little value for learning in this way, especially in language lessons and acquiring its skills. Rather, the teacher should use educational programs and platforms that provide design services for educational materials and interactive activities to improve distance learning quality in the concurrent direct and indirect classes.

Therefore, the teacher must develop his technical capabilities and improve his technological skills to succeed in the distance learning process. The use of online platforms, websites, the available programs on the Internet, and the design of study materials may greatly benefit achieving linguistic and cultural educational goals. In addition to providing the student the opportunity to practice the language and its skills through chat rooms, participatory groups for discussion, performing language tasks, language games, and other means can contribute to language learning success.

\section{Academic Materials and Educational Content:}

The teacher may face another challenge related to adapting the course materials to prepare for the virtual classes' traditional in-person classes. Teaching the skills of reading and listening through distance learning and exercises to measure comprehension and teaching and analyzing them will differ from teaching and presenting them to students in the direct classes that bring together the teachers and students in one educational environment. Besides, teaching vocabularies to activate and employ them in different contexts, such as using cards, pictures, stories, and tangible language games, will need to be reformulated and restructured through online programs, educational platforms, or sites to suit these activities and exercises for the virtual class. The teacher may need to double the effort and time to prepare his online materials compared to preparing his materials for the traditional classrooms, especially if he is not used to using educational websites and various technological programs.

There is a need to adapt the nature of the materials taught in language classes for non-native speakers, especially educational materials for Arabic language classes, its skills, methods of presenting and teaching them with the nature of virtual classes. For instance, the Arabic language grammar and teaching its linguistic and cultural structures are difficult for the student to understand and employ in his linguistic performance if they are not presented clearly and appropriately in its cultural context far from memorization, and taking into account the common challenges when teaching a new language and the challenges related to distance learning methods. All this requires the teacher to devote a lot of time and effort if he is truly seeking to achieve educational goals at the required level as in his natural 
educational environment or at least at its lowest levels. Therefore, teaching a second language is not easy and needs extra skills and preparation; this reflects the difficulty of online teaching of languages.

\section{Challenges Related to the Nature of Language Teaching}

\section{Methods of language teaching:}

Teaching a language has an educational, methodological, and stylistic feature that distinguishes it from other educational fields, especially teaching the language to non-native speakers (see: Kharma, 1988; Al-Musa, 2003; Aref, 2015; Abdul Karim, 2017). It is necessary to consider the functional principles in choosing educational content and presenting and teaching it to students, as functional principles represent the goal and teaching language (Abdo, 1990). It is also necessary to consider the international standards such as ACTFL standards and the European framework, which divides students into levels according to their linguistic competencies and ability to perform language functions and the curriculum's design and the educational activities. Thus, teaching the language to non-native speakers has directions, methods, curricula, and considerations that must be taken into account through the educational process in its natural conditions in the traditional classes that bring together the teacher and the student in the classroom. All of this must be considered in distance learning. Teachers find it challenging to pay attention to these principles in distance teaching, especially the method of presenting educational materials and displaying their content, which facilitates students' learning of the language and acquiring its skills, vocabularies, structures, and linguistic performance cultural development.

In addition to neglecting the practical aspects of language in distance learning, the student will not practice the language in its community or its cultural environment. Therefore, most of the student's time will be limited to the theoretical side of learning the language. As a result, teachers will be responsible because it requires them to provide interactive educational material and create opportunities to interact with the language's culture in various means to compensate for the lack of in-country learning through distance learning classes.

\section{Linguistic and Cultural Peculiarity:}

The linguistic and cultural peculiarity of teaching Arabic to non-native speakers is one of the main challenges of distance learning. This is represented in teaching its grammar, structure, vocabularies, and language skills, which should be integrated when teaching them to ensure successful learning that leads the student to achieve the goal of language acquisition and practice it in the community. Teaching language sounds through distance learning and pronouncing the vocabularies through direct or indirect lessons may not be appropriate or useful for some students, especially for junior students. Many of them need to closely see the teacher during phonetics classes, especially for the adjacent sounds that are difficult to distinguish, such as SIEN and SAD / DAL and DAAD, and the sounds that are not used in their languages as AIN, GHAIN, and DAAD.

Teaching vocabularies, especially the intangible vocabulary, may be useful in expressing it as body language or acting in the classroom or other methods that may not be possible through distance learning or may need to explain it for a longer time than the regular class.

Also, teaching grammar structures, which many students complain about the difficulty of acquiring in the normal situation, may seem more difficult on the Internet, even if some platforms and programs provide an electronic board or the possibility of sharing the presentation. The visual and written interaction between the professor and students may facilitate learning grammar better in regular classes. Some students may face challenges in understanding and learning grammar, and some teachers may experience challenges in presenting them to students online and preparing their materials, which may require double the time than regular classes.

The role of interactive and cooperative learning among students in practicing language and its skills, its positive impact on improving their language level, and practicing what they learn in the classroom in an interactive cultural format should not be overlooked. Although some educational platforms provide the Breakout Room feature as in the Zoom app, they do not achieve the same result as real interaction between students in regular classes in a real linguistic and cultural learning environment that has a clear impact on students' communication using the language and acquiring its skills.

\section{Correcting students' mistakes and continuous evaluation:}

Teaching a language to non-native speakers requires a continuous evaluation of students' performance and language production by observing their performance in direct classes or performing oral and written assignments; this also requires correcting students' linguistic and structural errors while practicing the language performing their duties. It includes masculinization and femininization errors, articles, mistakes in formulating and synthesizing the sentence elements, or not using the appropriate preposition or the appropriate verb tense, and this is in addition to the errors related to pronouncing vocabularies or using it in inappropriate contexts and many other errors that learners of Arabic and other languages make while practicing the language.

Perhaps this correction takes many forms, including direct or explicit correction, reformulation, request clarification, repetition, etc. Many teachers find it difficult to follow up on their students' correction and constantly evaluate distance learning. Virtual communication does not allow the possibility of continuous correction for students or visual communication difficulty. The teacher intends to draw his attention to his mistake without embarrassing him in front of his colleagues, especially through oral performance. Whereas this procedure may take more time to correct mistakes than the regular classes, it is less difficult to correct and evaluate a student's written production. Therefore, some 
teachers avoid the correction process in distance learning of language or correct less than usual or less than they are supposed to. Thus, it is difficult to achieve the goal of conducting the necessary correction process in language education classes, especially language teaching to non-native speakers, but somewhat essential to improve the student's level of linguistic production and achieve linguistic accuracy in producing the learned language, which is no less important than attaining language fluency.

\section{Challenges Related to the Nature of Distance Learning}

The most important challenges of this learning type intersect with the challenges of E-Learning (see: Rodny, 2002; Al-Hawamdeh, 2011; Al-Otaibi, 2006; Al-Jamlan, 2009). It includes:

1-Financial Cost:

The student and teacher need technological tools such as computers or smartphones, Internet packages, a camera, and other equipment to be used in the virtual classroom directly or indirectly. There is also a need to conduct lectures on websites and online platforms such as Microsoft Teams, Canvas, and Zoom, which take at least an hour of uploading written and visual materials such as texts, presentations, and educational videos on Google Drive or downloading it from YouTube. In addition to that, there is a need to form participatory activities on some sites such as Vialogues and designing an educational video using websites and software like Camtasia, or designing a language game using websites like Kahoot and Quizizz. All of them need internet data packages and devices to be used in distance learning, which is costly for the teacher and students.

2-Internet Speed:

Teachers and students may face problems with internet speed or signal strength, which negatively affects the communication process's achievement and sustainability.

3-Information security and confidentiality, and preserving the privacy of classrooms and their educational materials, as cyber attacks may occur, especially during the performance of online exams.

4- The reliability of examination results, especially if there is no direct supervision on students during the written exams, as students may resort to various means of assistance or cheating. Therefore, the test result does not measure the real level of students 'performance in these examinations.

5- Students will be tired by sitting for long periods in front of a computer screen or phones to follow their classes, especially since many language programs have no less than 4 hours of daily teaching hours apart from performing the tasks and duties that are required outside the class time.

\section{SugGeSTED SOLUTIONS AND RECOMMENDATIONS}

The presence of such challenges in distance learning of language classes may impede the lesson's continuation. Thus, failure to achieve the planned goals or achieving the lowest levels could be an outcome. Then students will not receive the benefit that they pursue through direct language classes. As a result, students will not improve their language skills or their linguistic and cultural level. These challenges have a clear impact on the language learning process and how students benefit from the language classes online. There are some solutions and suggestions that would meet these challenges and mitigate their negative effects on the success of the language class:

1- To motivate students and encourage them during this type of education, psychological preparation is necessary for distance learning success under the current circumstances. It is preferable if the first lesson of each week to be a direct lesson in which teachers motivate students and encourage them to continue learning.

2- The use of synchronous and non-synchronous distance learning did not pressure students to adhere to direct attendance and consider the geographical and time differences.

3- Teachers must set their goals and plan well for this type of education to ensure success. They can decide the appropriate way to present the subject and achieve their goals. If completing the goal requires a direct meeting with students, it will be better to do. Otherwise, asynchronous distance learning methods will do the trick.

4- Using diverse teaching methods in direct classes so that students do not feel bored. The interactive element is required, and if it is not available, then using indirect classes is better. Moreover, teachers must organize the teaching process in the indirect classes by setting a weekly schedule. The students are assigned to perform tasks and duties related to the educational materials they receive during the week, whether they are texts, educational videos, or academic, cultural activities.

5- It will be useful to use the recording feature on online platforms and communication programs to record simultaneous language lessons so that students can refer to them in case of any technical problem that prevents them from continuing the lesson.

6- The language lesson's objectives must be clear to the student before embarking on direct lessons and the tasks to focus on during the lesson time and not get distracted. Students need this in the virtual classes more than the regular classes due to the inability to interact.

7- It is more useful to turn the camera on when talking with students during direct language classes, whether it is listening, reading, grammar lesson, or vocabularies. Many students try to pay attention to the way the words are pronounced and the phonetics or the teacher's expressions during the speech, and they may try to understand it from lip movement or body language; this is linked to the students' learning strategies. 
8- To follow language lessons simultaneously and non-simultaneously with an oral or written activity to ensure that students understand the language lessons presented. They can then assess their experience to improve the level of activity and plan for the new lesson.

9- Ensure that the audio and video lesson materials are ready and that they can be run via communication programs or online educational platforms before starting the class to avoid any technical problem that may occur. Teachers have to be flexible in dealing with any problem that may occur when dealing with alternative plans.

10- Using diverse activities of language lessons and training so that students do not feel bored, and providing various interactive activities that employ the lesson's content and invest it in linguistic activities that motivate students to the upcoming classes. Teachers may use original videos or design educational videos by using applications such as a screencast and Camtasia. Furthermore, teachers may create a text for listening and make a group discussion among students by answering written questions as in the Vialogues website, using a presentation, Linguistic videos, pictures, or games like Kahoot Quizlet. Simultaneously, teachers can share it with their students in synchronous or asynchronous classes to interact with the educational content and draw their attention and facilitate the acquisition of language skills and its elements to practice the language quickly.

11- Educational institutions must train their teachers for this type of education by holding training courses and developing teachers' technological and technical skills. Schools and universities should also train their students on this type of education by using it in the classrooms regularly.

12- Workshops should be held for language teachers to exchange their experiences in distance language teaching and develop useful means and easier ways to present the language and its skills to students in a better educational and cultural format. Teachers need to learn how to benefit from other language experiences and educational sites to teach languages online and develop them according to educational institutions' goals.

\section{CONCLUSION}

This study showed the most critical challenges that face the language learner and teacher, especially the Arabic language, through distance learning classes. Also, it identified the challenges related to the nature of teaching languages generally and the Arabic language in particular. It also discussed the most critical challenges associated with distance learning and its impact on the language class's success and objectives. Furthermore, this study presented several solutions and suggestions that could help face these challenges and mitigate their negative impact on the language class and achieve its desired goals.

\section{REFERENCES}

[1] Abdo, D. (1990). Toward functional teaching of the Arabic language (2nd Edition.). Al Karmel House, Amman.

[2] Abu Musa, M., \& Al-Sous, S. (2012). Blended education between traditional and E-Learning (1st Edition). Academics for publication and distribution. Amman.

[3] Al- Kilany, T. (2011). Blended Learning Strategies (1st Edition.). Lebanon Library. Beirut.

[4] Al Qudum, M. (2016). The impact of technology and modern means of communication on learners of Arabic for non-Arabic speakers. Ph.D. thesis. Supervision of Muhammad Al-Qudah. The University of Jordan.

[5] Al-Hawamdeh, M. (2011). Obstacles to using E-Learning from the point of view of faculty members at Al-Balqa Applied University. Damascus University Journal of Educational Sciences, Volume 27 (Issues $1 \quad$ and 2 ). http://www.damascusuniversity.edu.sy/mag/edu/images/stories/803-831.pdf.10 Sep2020.

[6] Al-Jamlan, M. (2009). E-Learning: Issues and Challenges (1st Edition). Arab Network for Open and Distance Learning. Amman.

[7] Al-Khan, B. (2005). E-Learning Strategies. Shua'a for Publishing \& Science. Aleppo.

[8] Al-Mousa, N. (2003). Methods: Approaches and Models in Teaching the Arabic language (1st Edition). Alshrouq House. Amman, p.61.

[9] Al-Omari, M. (2014). E-learning and its modern technologies. Deanship of Scientific Research and Postgraduate Studies, Yarmouk University. Irbid. Jordan.

[10] Al-Otaibi, N. (2006). Obstacles to E-Learning in the Ministry of Education from the viewpoint of educational leaders. Unpublished Master's thesis, Mu'tah University. Jordan.

[11] Amer, T. (2007). Distance and Open Education (1st Edition.). Al-Bazouri Scientific Publishing House, Amman. Jordan.

[12] Aref, H., \& Bougamlin, L. (2015). Modern approaches to teaching Arabic, from language education to teaching language communication. Al-Athar Magazine, Volume14 (Issue23), p.21-30 https://www.asjp.cerist.dz/en/article/47754. 25Aug 2020.

[13] Bin Abdul Karim, B. (2017). Foundations and principles in teaching and learning Arabic according to the textual approach. Journal of Studies of the Faculty of Humanities and Social Sciences, University of Constantine, Volume 4 (Issue 7). https://www.asjp.cerist.dz/en/article/37782 .12 Sep2020.

[14] Brawn, D. (1994). Foundations of language learning and teaching. Translated by Abdo Al-Rajhi and Ali Ahmed Shaban. Arab Renaissance House for Printing and Publishing. Beirut.

[15] Farkouh, S., \& Attiyat, M. (1989). Distance Learning: Its concept and Usage. Ministry of Education, Oman. Jordan.

[16] Haisa, Sh. (2019). The effect of user interaction patterns in the E-Learning environment on developing reading skills for nonnative speakers, "beginner level." Master Thesis. Supervision of Abdullah Muhammad Ahmad. The University of Jordan.

[17] Kharma, N., \& Hajjaj, A. (1988). Foreign languages are taught and learned. Knowledge world. Kuwait. 
[18] Nageh, A. (2018). The foundations of learning the second language and ways to achieve it between familiarity and investigation. International Journal of Educational and Psychological Studies, Issue $2, \quad$ p.180 https://www.democraticac.de/?p=55275.17 Aug 2020.

[19] Rodny, s. (2002). The integration of instructional technology into public education- Promises and challenges. Education technology. 1(5), 11. https://www.jstor.org/stable/44428716?seq=7\#metadata_info_tab_contents 20 Sep 2020.

[20] Salem, A. (2004). Education and E-Learning Technology (1st Edition). Al-Rashed Library. Riyad

Dalal Mohammad Al-Assaf was born in Amman / Jordan, in 1987. She obtained a master's degree in teaching Arabic to nonnative speakers with excellent grade from the University of Jordan in 2012. She obtained a BSc. Arabic Language from the University of Jordan - Merit Excellent in 2009.

She has been working in the field of teaching Arabic to non-native speakers from 2010 to now, during which She taught several levels of beginner, intermediate and advanced levels in classical and colloquial. She working now as a faculty member at the Language Center at the University of Jordan, and She worked in the summer program of Columbia University / Amman from 2010 to 2015, and She worked in the Middlebury / Jordan program from 2013 until now, and She worked in the summer program of the University of Middlebury / California in 2019, and worked Trainer for teachers of teaching Arabic to non-native speakers at the University of Jordan. She participated in preparing the educational curricula in the Middlebury program, as well as participating in conferences, workshops and training courses locally and internationally. She has obtained an International Examiner Certificate in Oral Proficiency from the American Council on Language Teaching (ACTFL) since 2015.

She has published a book and a number of peer-reviewed scientific papers in local and regional magazines, as well as several articles in electronic journals. Such as:

- Published book, Investment of Colloquial in the teaching Grammatical Method FOR NON-Arabic Speakers, Dar Jlis al-Zaman, 2015, a master's thesis under the supervision of Dr. Suha Nuja / 2012

- A research paper, Investing Jordanian Colloquial in Teaching Classical Arabic Morphological Structure (Agent Noun as an Example) / Journal of Studies - Humanities and Social Sciences / University of Jordan / Volume 43 / Issue 3/2016.

- Research a joint publication, Using Linguistic Games in Teaching Vocabulary Items for Non-Native Speakers of Arabic, Journal of Studies Ammar Thalji University / Laghouat University - Algeria, Issue 60, 2017. 